\title{
Unresectable Renal Pelvis Urothelial
} Carcinoma

National Cancer Institute

\section{Source}

National Cancer Institute. Unresectable Renal Pelvis Urothelial Carcinoma. NCI

Thesaurus. Code C158588.

Renal pelvis urothelial carcinoma that is not amenable to surgical resection. 